J. Clin. Chem. Clin. Biochem.

Vol. 14, 1976, pp. 23-26

\title{
Improvements and Simplifications of the Ozonolysis-Schiff Staining Method for Plasma Lipoproteins on Cellulose Acetate
}

\author{
By $A$. Uldall \\ Department of Clinical Chemistry, Geriatric Unit, De Gamles By, Copenhagen, Denmark
}

(Eingegangen am 14. Mai/3. September 1975)

Summary: Modifications of the ozonolysis and Schiff staining of plasma lipoproteins reduce 11 pre-spectrometric steps to 3. Picrate denaturation of the lipoproteins and absorption spectrometry directly on the wet opaque membrane increase the sensitivity; the volume of sub-specimen needed per length of application site is reduced from 0.7 to $0.1 \mu \mathrm{l} / \mathrm{mm}$. Reasonably good proportionality between the total lipoprotein concentration and the spectrometric findings are obtained. Two specimens were obtained at an interval of 8-13 days from each of 10 patients; for the arbitrary substance fraction of $\alpha$-, pre $\beta$-, and $\beta$-lipoproteins in plasma the between-series intra-individual standard deviations were $0.021,0.023$ and 0.032 respectively.

\section{Verbesserungen und Vereinfachungen von Ozonolyse und Schiff-Färbung für Plasmalipoproteine auf Celluloseace- tatfolien}

Zusammenfassung: Modifikationen von Ozonolyse und Schiff-Färbung für Plasmalipoproteine reduzieren die 11 präspektrometrischen Schritte auf 3. Pikratdenaturierung der Lipoproteine und Absorptionsspektrometrie direkt an der feuchten und trüben Membran erhöhen die Sensibilität; das notwendige Applikationsvolumen ist von 0,7 auf $0,1 \mu \mathrm{l} / \mathrm{mm}$ reduziert. Eine befriedigende Proportionalität zwischen der Gesamtlipoproteinkonzentration und den spektrometrischen Resultaten ist gegeben. Mit einem Intervall von 8-13 Tagen wurden zwei Proben von je zehn Patienten entnommen; die entsprechenden interseriell-intraindividuellen Standardabweichungen waren 0,021, 0,023 und 0,032 für das arbiträre Stoffmengenverhältnis der $\alpha$-, prä $\beta$ - und $\beta$-Lipoproteine im Plasma.

The most frequently used method of preparation for the measurement of lipoprotein after electrophoretic separation consists of treatment with supersaturated alcoholic solutions of coloured lipophilic azo-compounds, e.g. 'Oil-Red-O' or 'Sudan Black'. However, owing to unspecific staining of protein $(1,2)$ and elution of lipids in the alcoholic reagents (3), an alternative procedure is needed.

The doublesbond containing carboxylates represent about $3 / 4$ of the total aliphatic carboxylates in plasma, and the unsaturation of the lipoprotein is the basis of Kohn's suggestion (4): ozonolysis of the double-bond, hydrolysis, and staining of the aldehyde groups formed. Postma \& Stroes (5) described a routine piocedure for cellulose acetate similar to that of Kohn, but variable staining obtained by applying their technique led the author to modify the procedure. Complete drying of the cellulose acetate membrane before ożone treatment and ozone production by an ozone lamp is found to decrease the variation to some extent; but partial disappearance of the lipoprotein stain is found during rinsing and drying before spectrometry. The present staining technique solves this problem. The sensitivity is increased about 7 times, and the number of procedural steps are reduced from 11 to 3 .

\section{Materials and Methods}

\section{Reagents}

Proteins were denatured by $R$-Picrate, $40 \mathrm{mmol} / \mathrm{l}$ produced by dissolving picric acid, in deionized water. The staining reagent was 'Schiff's Reagenz auf Aldehyde' Merck, Darmstadt, Germany, Art. No. 9034

\section{Apparatus}

Absorption spectrometer, Vitation densitometer (UFD 100), interference filter $573 \mathrm{~nm}$, recorder and accessories for measurement along the fractionation track (slit $3 \times 0.2 \mathrm{~mm}$ ), Vitatron, Dieren, The Netherlands.

Ozonisation chamber, containing dried silicagel, a propeller and the ozone lamp, OZ 4 (Phillips, Eindhoven, The Netherlands) was locally produced.

Electrophoretic separation

Fresh plasma from 12-hour fasting patients, was separated on cellulose acetate membrane, Sepraphore III (Gelman Instrument 
Company, Ann Arbor, Michigan USA) essentially as described by the manufacturer. However, the sub-specimen volume per length of application site was $0.1 \mu \mathrm{l} / \mathrm{mm}$, the electrophoresis chamber was cooled and - in order to save cellulose acetate - wicks were mounted (synthetic wash leather, housekeeping quality). Cellulose acetate membrane from Sartorius-Membranfilter $\mathrm{GmbH}$, 3400 Göttingen, Germany may be used instead of the present brand.

Staining procedure and measurement

The membrane was placed for $0.6 \mathrm{ks}(10 \mathrm{~min})$ in R-Picrate, $40 \mathrm{mmol} / 1$, dried and exposed to ozone in the ozonization chamber for 1.8 to $4.5 \mathrm{ks}(1 / 2$ to $11 / 4 \mathrm{~h})$ depending on the construction of the ozonisation chamber. The membrane was transferred to a Petri dish containing 'Schiff's Reagenz auf Aldehyde', and allowed to remain there for $1.8 \mathrm{ks}(30 \mathrm{~min})$ or longer. The $\mathrm{ab}$ sorption spectrometry along the electrophoretic track, on the wet membrane was performed on the same day; when the membrane is stored wet with 'Schiff's Reagenz auf Aldehyde', in a plastic bag at $4^{\circ} \mathrm{C}$ the colour is nearly stable for one month; however, the background staining may increase slowly. The borders between the lipoprotein fractions are defined according to fixed relative distances between the peaks of $\alpha$-lipoprotein and $\beta$-lipoprotein on the recorder paper (details will be supplied upon request).

\section{Definitions of the 'series'}

Generally, the two separations of a within-series duplicate were made on different sheets of cellulose acetate and in different electrophoresis chambers, but were stained together. The betweenseries variations are based on means of within-series duplicates from different days of analysis, using the same batch of cellulose acetate, but not necessarily the same reagents. Usually, the same technician performed both determinations.

\section{Quantities and units}

A quantity is described in the format System-Component, kind of quantity $=$ numerical value $X$ unit. For shortness, the units $\mathrm{mol} / \mathrm{l}$ and $\mathrm{mmol} / \mathrm{l}$ imply the kind of quantity substance concentration. Analogously, Celsius temperature is omitted when ${ }^{\circ} \mathrm{C}$ is used and time difference by the unit ks.

In tables each heading is given the form $\frac{\text { quantity }}{\text { unit }}$ so that only numerical values are given in the field.

\section{Results and Discussion}

Between-series variation of the sum of the concentrations of the lipoprotein fractions measured on the recorded absorbance curve.

The area between the absorbance curve and the baseline, measured along the fractionation track, is designated the curve area. Variation of the curve area for a given specimen is caused by variation in the measurement of the $2 \mu \mathrm{l}$ sub-specimen (length of the applicator was $20 \mathrm{~mm}$ ), during transfer to the membrane, in the geometry of the fractions after electrophoresis, chemical procedure, and spectrometry. From 20 days determination of a plasma pool stored at $-80^{\circ} \mathrm{C}$ the between-series coefficient of variation was 0.08 .

\section{Analytical variation of the measurements of the lipopro- tein fractions}

Table 1 shows the analytical variations of the present method. The between-series standard deviations $\left(s_{b+s}\right)$

Tab. 1. Analytical variation of plasma lipoproteins fractionated on cellulose acetate and stained by 'Schiff's reagent' after ozonolysis of double-bonds ${ }^{1}$ )

\begin{tabular}{|c|c|c|c|c|c|}
\hline \multirow[t]{4}{*}{ Type of variation } & \multirow[t]{4}{*}{ Symbol } & \multirow{4}{*}{$\begin{array}{l}\begin{array}{l}\text { Number of } \\
\text { patients }\end{array} \\
\frac{1}{n}\end{array}$} & \multicolumn{3}{|c|}{ Standard deviation for the arbitrary substance fraction of lipoprotein in plasma } \\
\hline & & & \multirow[b]{3}{*}{$\alpha$-lipoprotein } & \multirow[t]{2}{*}{1} & \multirow[b]{3}{*}{$\beta$-lipoprotein } \\
\hline & & & & & \\
\hline & & & & preß-lipoprotein & \\
\hline 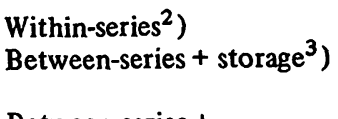 & $\begin{array}{l}s_{w} \\
s_{b+s}\end{array}$ & $\begin{array}{l}77 \\
29\end{array}$ & $\begin{array}{c}0.016 \\
0.028 \\
(0.016)\end{array}$ & $\begin{array}{c}0.015 \\
0.026 \\
(-0.012)\end{array}$ & $\begin{array}{c}0.016 \\
0.035 \\
(-0.005)\end{array}$ \\
\hline $\begin{array}{l}\text { Between-series + } \\
\text { intra-individual }+ \\
\text { blood withdrawal }+ \\
\text { plasma-preparation }{ }^{4} \text { ) }\end{array}$ & $s_{b+i}$ & 10 & 0.021 & 0.023 & 0.032 \\
\hline
\end{tabular}

1) The mean values were essentially equal to those of the reference intervals: $0.344(0.050), 0.172(0.047)$ and $0.484(0.047)$ respectively; the standard deviations are given in parentheses; details will be supplied upon request. The data were all obtained on cellulose acetate, batch No. 80561. The standard deviations given in the field of the table are valid for the mean $(\bar{f})$ of a within-series double determination $\left(f_{1}\right.$ and $\left.f_{2}\right)$.

$\left.{ }^{2}\right)$ The data were recorded during a three-month period and the analyses were performed by two technicians.

$$
s_{\mathrm{w}}=\frac{1}{\sqrt{2}} \sqrt{\sum_{i=1}^{n} \frac{\left(f_{1}-f_{2}\right)^{2}}{2 n}}
$$

3) The analyses were performed before and cfter 1-9 days' storage of the specimens at a Celsius temperature $=4^{\circ} \mathrm{C}$, giving the duplicate means $f_{\text {be }}$ and $f_{\text {af }}$ respectively.

$s_{\mathrm{b}+\mathrm{s}}=\sqrt{\sum_{i=1}^{n} \frac{\left(\bar{f}_{\mathrm{be}}-\bar{f}_{\mathrm{af}}\right)^{2}}{2 n}}$

The means of the differences $\left(\bar{f}_{\mathrm{be}}-\bar{f}_{\mathrm{af}}\right)$ are given in parentheses. The value of this mean for $\alpha$-lipoprotein is significantly different from zero $(P<0.05)$.

The value of this mean for $\alpha$-lipoprotein is significantly different from $(P<0.05)$.

$\left.{ }^{4}\right)$ Two specimens were obtained at an interval of 8-13 days from each of 10 patients showing only non-systematic differences in the concentrations of triglyceride and cholesterols of less than 0.2 and $0.5 \mathrm{mmol} / 1$ respectively. Their lipoprotein data before and after were $\bar{f}_{\mathrm{I}}$ and $\bar{f}_{\mathrm{II}}$ respectively.

$s_{\mathrm{b}+\mathrm{i}}=\sqrt{\sum_{i=1}^{n} \frac{\left(\bar{f}_{\mathrm{I}}-\bar{f}_{\mathrm{II}}\right)^{2}}{2 n}}$. 
Tab. 2. Curve area as a function of lipoprotein concentration

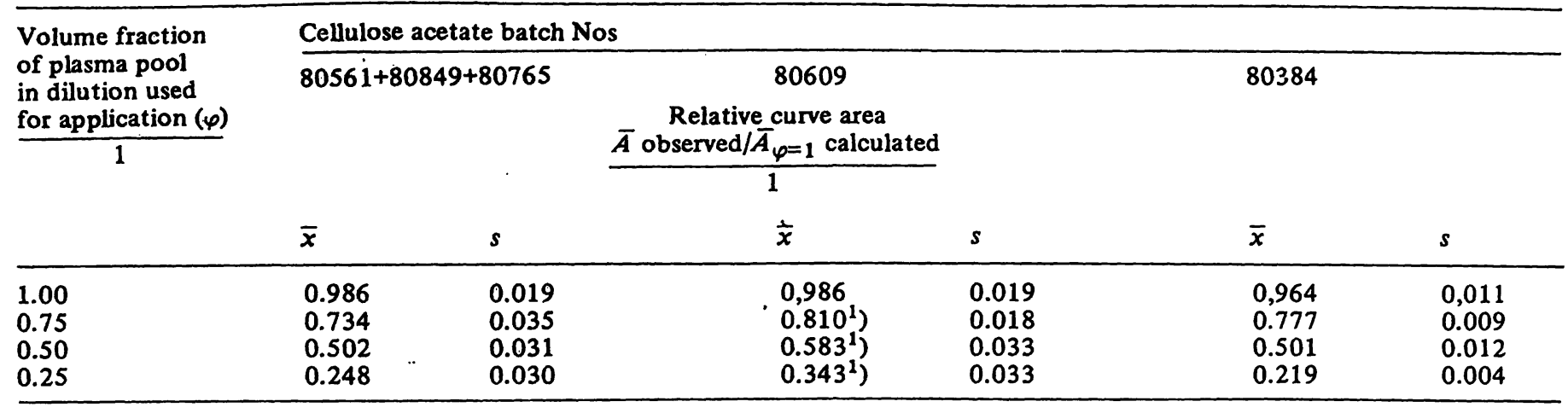

1) Significantly different from the mean of batch Nos 80561,80849 , and $80765(P<0.01)$

Plasma pools from employees were stored in small glass tubes at $-80^{\circ} \mathrm{C}$. Before use a pool was thawed and carefully mixed. Using sodium chloride, substance concentration $154 \mathrm{mmol} / 1$ in deionized water (or sodium chloride, $65 \mathrm{mmol} / 1$ and trisodium citrate $16 \mathrm{mmol} / \mathrm{l}$ in deionized water) a series (4-6 elements) of dilutions was produced and sub-specimens were immediately determined in duplicate, using a volume per length of application site of $0.15 \mu \mathrm{l} / \mathrm{mm}$. A regression line was calculated using the volume fraction $(\varphi)$ of plasma in the dilution as abscissa value and the observed duplicate mean curve area $(\bar{A})$ values are given relative to the calculated curve area corresponding to $\varphi=1$ of the regression line $\left(\bar{A}_{\varphi=1}\right)$. The above procedure was performed three times in different series for each batch of cellulose acetate; $x$ and $s$ are the arithmetic mean and standard deviation of nine or three results (each being duplicated means).

are useful in the quality control of the routine performance of the analysis in spite of the slight changes in concentration during storage at $+4^{\circ} \mathrm{C}$.

\section{Lipoprotein denaturation by picrate and by à phenol- containing reagent}

The introduction of protein denatured with picrate more than doubled the curve area as compared to the method of Postma \& Stroes (5). The phenolic denaturation technique of Grabner et al. (6) gave curve area values about $2 / 3$ of that obtained by the present method. Proteins are only partly denatured by the phenolic reagent, and poor denaturation of some lipoproteins may explain the apparent better resolution of lipoprotein fractions rather than a less unspecific protein reaction as claimed by

Grabner et al. (6). The incomplete phenolic denaturation of albumin with bound non-esterified aliphatic carboxylates, and of lipoprotein (7) in the albumin zone may explain the absence of colour there.

\section{Absorption spectrometry on different batches of opaque cellulose acetate}

Spectrometry in opaque media has the advantage over that of clear systems of a highly useful increased sensitivity, but Beer's law is not strictly followed (8).
Table 2 shows that undiluted plasma $(\varphi=1.00)$ for each batch of cellulose acetate yield a value lower than the value obtained by linear regression of the curve area upon lipoprotein concentration; however, the pooled three batches, show acceptable proportionality between the two parameters and, their individual regression lines were close to each other. Batch No. 80609 shows significant differences from the pooled group; the structure of this membrane was clearly different from that of the other batches as chylomicrons left the application site. The mass density of the air-filled membrane for four of the five batches mentioned was $0.22 \mathrm{~kg} / \mathrm{l}$, but for batch No. 80384 it was $0.33 \mathrm{~kg} / \mathrm{l}$; the curve area given by the undiluted plasma pool was about 1.5 times that of the other batches. Presumably this is due to increased intramembrane reflection of light (8).

\section{Acknowledgement}

The author wishes to thank the staff for invaluable assistance, and especially Gerd Bentzen, medical technician, for her careful performance of the analytical work. 


\section{References}

1. Dyerberg, J. \& Hjфme, N. (1971), Clin. Chim. Acta 33, 458-461.

2. Torsvik, H., Boman, H., Bjermann, I., Harboe, M. \& Norum, K. R. (1972), Clin. Chim. Acta 42, 433-435.

3. Jencks, W. P., Durrum, E. L. \& Jetton, M. R. (1955), J. Clin. Invest. 34, 1437-1448.

4. Kohn, J. (1961), Nature 189, 312-313.

5. Postma, T. \& Stroes, J. A. P. (1968), Clin. Chim. Acta 22, $569-578$.
6. Grabner, W., Gronauer, W., Berg, G. \& Bergner, D. (1970), Clin. Chim. Acta 28, 299-310.

7. Philips, G. B. \& Wille, L. E. (1974), Clin. Chim. Acta 50, 425-430.

8. Goldman, J. \& Goodall, R. R. (1968), J. Chromatog. 32, 24-42.

\author{
Present address: \\ Lic. pharm. Adam Uldall \\ Depärtment of clinical chemistry, \\ KAS Herlev, \\ Turkisvej, \\ DK-2730 Herlev., Denmark
}

